\title{
ANÁLISE DA ARBORIZAÇÃO URBANA DE DUAS CIDADES DA REGIÃO NORTE DO ESTADO DE MATO GROSSO ${ }^{1}$
}

\author{
Danielucia Noya de Almeida² e Rubens Marques Rondon Neto ${ }^{3}$
}

\begin{abstract}
RESUMO - Este estudo teve por objetivo analisar a arborização viária de Colíder e Matupá, cidades da região Norte do Estado de Mato Grosso. Foram levantados 547 indivíduos, distribuídos em 15 famílias botânicas, 21 gêneros e 21 espécies; 66,7\% das espécies são exóticas à flora brasileira e 33,3\%, nativas. As espécies mais frequentes nas cidades avaliadas foram: Licania tomentosa (73,1\%), Ficus benjamina (6,6\%) e Pachira aquatica (4,2\%). Nas duas cidades, mais de $85 \%$ da população obteve diâmetro à altura do solo inferior a $0,4 \mathrm{~m}$ e mais de 75\% da população estava abaixo de 6,0 m de altura total, nas duas cidades. Os indivíduos plantados sob a fiação elétrica representaram menos de 50\% da população amostrada, nas duas cidades amostradas, e a altura média das árvores, sob a fiação, foi de 3,0 m (Matupá) e 4,7 m (Colíder). Mais de 85\% dos indivíduos tinham bifurcação abaixo de 1,80 m. A densidade de árvores $/ \mathrm{km}$ de calçada estimada nas cidades avaliadas variou entre 66,2 árvores/km (Matupá) e 71,3 árvores/km (Colíder). Os índices de diversidade de Shannon estimado foram 0,76 (Colíder) e 2,24 (Matupá). A largura das vias e recuos permitia o plantio de espécies de médio e grande portes. Contudo, são essenciais o planejamento da arborização urbana e a definição de critérios e técnicas adequadas para a realização de plantios e manutenções, nas cidades estudadas.
\end{abstract}

Palavras-chave: Arborização viária, Colíder e Matupá.

\section{ANALYSIS OF URBAN FORESTRY IN TWO CITIES OF THE NORTH REGION IN THE STATE OF MATO GROSSO}

\begin{abstract}
The present study aimed to analyze the roadside forestry of Colíder and Matupá, two cities of the northern region in the State of Mato Grosso. There were 547 individuals, distributed in 15 botanical families, 21 genera and 21 species. Over 66\% of these species are exotic to the Brazilian flora and 33.3\% are native. The species most frequent in the evaluated cities were: Licania tomentosa $(73,1 \%)$, Ficus benjamina (6.6\%) and Pachira aquatica (4.2\%). In the two cities, more than $85 \%$ of the population had a diameter at ground level inferior to $0.4 \mathrm{~m}$ and more than $75 \%$ of the population had a total height less than 6.0 $m$, in the two cities. The individuals planted under the electric wiring represented fewer than $50 \%$ of the population in the two sampled cities, and the average height of the trees under the wiring was $3.0 \mathrm{~m}$ (Matupá) and $4.7 \mathrm{~m}$ (Colíder). More than 85\% of the individuals had presented bifurcation below $1.8 \mathrm{~m}$. The density of trees $/ \mathrm{km}$ of sidewalk estimated in the evaluated cities varied between 66.2 trees $/ \mathrm{km}$ (Matupá) and 71.3 tree $/ \mathrm{km}$ (Colíder). The Shannon diversity index estimate was 0.76 (Colíder) and 2.24 (Matupá). The width of the streets and recesses allows the planting of medium to large size species. However, urban forestry planning and a definition of criteria and techniques appropriate to the accomplishment of planting and maintenance are essential.
\end{abstract}

Keywords: Roadside reforestation, Colíder e Matupá.

\section{INTRODUÇÃO}

O aprofundamento dos estudos relativos à arborização urbana se faz cada vez mais necessário, à medida que esses comprovam a contribuição da arborização na melhoria da qualidade ambiental, gerando efeitos psicológicos e físicos positivos. A arborização urbana em vias públicas é fundamental para manutenção da qualidade de vida, proporcionando conforto aos habitantes das cidades, pois contribui com a estabilização climática, embeleza, fornece abrigo e alimento à fauna

\footnotetext{
${ }^{1}$ Recebido em 03.05.2009 e aceito para publicação em 02.03.2010.

${ }^{2}$ Secretaria de Estado do Meio Ambiente-SEMA, Mato Grosso, Brasil. E-mail: <noyadani@yahoo.com.br>.

${ }^{3}$ Universidade do Estado de Mato Grosso, UNEMAT, Brasil. E-mail: <rubensrondon@yahoo.com.br>.
} 
e sombra e lazer às ruas e avenidas das cidades (McHALE et al., 2007). Entretanto, em muitas situações o planejamento urbano deixa de incluir a arborização como atividade a ser devidamente executada (GONÇALVES et al., 2004). A falta de diretrizes para a arborização urbana permite que iniciativas particulares pontuais e desprovidas de conhecimento técnico tomem espaço com plantios irregulares de espécies sem compatibilidade com o planejamento anterior. Essa situação é traduzida em perda da eficácia da arborização em transmitir conforto físico e psíquico, trazendo infortúnios e transtornos, como: plantios desordenados, resultando em distribuição irregular das espécies (YANG et al., 2005; ROSSATTO et al., 2008), uso excessivo de espécies exóticas (BORTOLETOetal., 2007) emanutenção deficiente(ROCHA et al., 2004), o que acarreta conflitos entre as árvores e os elementos urbanos, principalmente a rede de distribuição de energia (VELASCO et al., 2006).

Em Mato, via de regra, a criação das cidades é recente, oriundas de núcleos de colonizadores advindos de outras regiões do Brasil, principalmente da Região Sul do país (MATO GROSSO, 2005). Os imigrantes trouxeram consigo e implantaram, nessas regiões, hábitos e espécies utilizadas na arborização urbana daquela região, sem haver estudos prévios relacionados ao planejamento adequado da arborização urbana nessas cidades.

Por conseguinte, pela premência este trabalho teve como objetivo analisar a situação atual da arborização urbana em duas cidades da região Norte do Estado de Mato Grosso, a fim de obter subsídios que possam servir de base na discussão e elaboração de leis municipais que visem orientar e regulamentar a atividade.

\section{METODOLOGIA}

O estudo foi realizado nas cidades de Colíder e Matupá, ambas localizadas no extremo Norte do Estado de Mato Grosso. Com 54 municípios, essa região compreende a maior mesorregião de Mato Grosso em números de municípios e em extensão territorial (MATO GROSSO, 2005). A Tabela 1 apresenta informações referentes aos aspectos geográficos e políticos dos dois municípios estudados.

Pela classificação de Köppen, a região Norte do Estado de Mato Grosso apresenta clima tipo Awi e temperatura média anual em torno de $25,4{ }^{\circ} \mathrm{C}$, com precipitação média anual em torno de 2.200 mm (MATO GROSSO, 2008).

Os dados foram coletados através de amostragem aleatória simples e anotados em uma ficha de campo previamente preparada. Os levantamentos foram realizados no primeiro semestre do ano de 2008.

As informações coletadas consideraram os seguintes aspectos: localização e identificação da espécie, altura total e altura da bifurcação mensuradas com régua graduada, circunferência a 50 cm de altura do solo (CAS) mensurada com fita métrica, diâmetro da copa (sentidos N-S e E-W), distância entre as árvores e proximidade das infraestruturas urbanas, medidos com trena. Ressaltase que a circunferência foi mensurada a $50 \mathrm{~cm}$ de altura de solo, para que, dessa forma, fossem inclusos na amostragem indivíduos em diferentes estágios de desenvolvimento (desde mudas até indivíduos adultos).

Para caracterizar o ambiente envolvido na arborização urbana foram procedidas as seguintes medições: largura e comprimento da via, largura da calçada, largura do recuo (meio-fio até o muro), distância dos postes ao meio-fio, altura da fiação telefônica e altura da fiação de alta e baixa tensão.

A frequência relativa de cada espécie foi calculada pela razão entre o número de indivíduos da espécie e o número total de espécimes, multiplicada por 100. As espécies amostradas foram classificadas quanto à origem, mediante consultas bibliográficas, como: Correia

Tabela 1 - Dados geográficos e políticos das cidades de Colíder e Matupá, situadas na região Norte do Estado de Mato Grosso, utilizados para análise da arborização urbana.

Table 1 - Geographical and political data of the cities of Colíder and Matupá, located in the northern region of Mato Grosso State used for analysis of the urban forestry.

\begin{tabular}{lcccc}
\hline Município & Ano de criação & Área geográfica $\left(\mathrm{km}^{2}\right)$ & Área urbana $\left(\mathrm{km}^{2}\right)$ & $\mathrm{N}^{\circ}$. de habitantes \\
\cline { 3 - 5 } & & & Urbana & Rural \\
\hline Colíder & 1979 & $3.038,25$ & 8.17 & 19.423 \\
Matupá & 1988 & $5.151,85$ & 5,11 & 11.289 \\
\hline
\end{tabular}

Fonte: MATO GROSSO, 2008.

Source: MATO GROSSO, 2008.

Revista Árvore, Viçosa-MG, v.34, n.5, p.899-906, 2010 
(1984), Lorenzi (2002), Carvalho (2003), Lorenzi et al. (2003), Carvalho (2006), Carvalho (2008) e Lorenzi (2008). As espécies foram classificadas, também, quanto à aptidão para a alimentação humana, baseada nas pesquisas bibliográficas citadas anteriormente e em Shanley (2005) e Lorenzi et al. (2006). Os indivíduos inventariados foram classificados quanto ao porte, de acordo com Mascaró e Mascaró (2005). Foi estimado o Índice de Diversidade de Shannon (IDS).

\section{RESULTADOS E DISCUSSÃO}

\subsection{Composição florística da arborização viária}

O percurso realizado nas duas cidades avaliadas totalizou $8.850 \mathrm{~m}$ percorridos e possibilitou coletar dados da arborização em 13 vias públicas, sendo seis vias em Matupá (2.350 m) e sete em Colíder (6.200 m). Na amostragem foram quantificados 547 indivíduos, pertencentes a 21 diferentes espécies, nas duas cidades. Os resultados são apresentados na Tabela 2.

O número de espécies encontradas na arborização viária das duas cidades estudadas pode ser considerado baixo em relação a outros estudos já realizados, como: Santos/SP - 65 espécies (MENEGHETTI, 2003), Nova Iguaçu/RJ - 59 espécies (ROCHA et al., 2004) e Curitiba/ PR - 370 espécies (BIONDI e MACEDO, 2008).

Milano (1984) recomendou que cada espécie não deve ultrapassar 15\% do total de indivíduos da população arbórea, com o intuito de minimizar riscos de pragas e doenças, além de intempéries às quais as espécies possam ser submetidas. Licania tomentosa apresentou frequência relativa acima desse limite em ambas as cidades. No entanto, foi constatado elevado número de espécies com baixa frequência. Em Matupá e Colíder, cinco e seis espécies, respectivamente, apresentaram frequência abaixo de 1,0\%.

Tabela 2 - Distribuição quantitativa das espécies encontradas na arborização viária das cidades de Matupá e Colíder, situadas na região Norte do Estado de Mato Grosso, com os respectivos nomes científicos e comuns, quantidade de indivíduos amostrados (n), frequência relativa (FR) (\%) e origem (N = nativa e E = exótica).

Table 2 - Quantitative distribution of the species found in the road forestry of the cities of Matupá and Colíder, located in the northern region of the State of Mato Grosso, with their scientific and common names, quantity of individuals sampled $(n)$, relative frequency $(F R)(\%)$ and origin $(N=$ native, $E=$ exotic $)$.

\begin{tabular}{|c|c|c|c|c|c|c|}
\hline \multirow[t]{3}{*}{ Família/Nome científico } & \multirow[t]{3}{*}{ Nome comum } & \multicolumn{4}{|c|}{ Cidade } & \multirow[t]{3}{*}{ Origem } \\
\hline & & \multicolumn{2}{|c|}{ Matupá } & \multicolumn{2}{|c|}{ Colíder } & \\
\hline & & $\mathrm{n}$ & FR & $\mathrm{n}$ & FR & \\
\hline AnacardiaceaeAnacardium occidentale L. & Cajueiro & 1 & 0,84 & - & - & $\mathrm{N}$ \\
\hline AnacardiaceaeMangifera indica L. & Mangueira & 17 & 14,29 & 1 & 0,23 & $\mathrm{E}$ \\
\hline AnacardiaceaeSpondias dulcis Forst. & Cajá-manga & 1 & 0,84 & - & - & $\mathrm{E}$ \\
\hline PinaceaePinus sp & Pinheiro & 8 & 6,72 & - & - & $\mathrm{E}$ \\
\hline ArecaceaeRoystonea oleracea & Palmeira imperial & 9 & 7,56 & 1 & 0,23 & $\mathrm{E}$ \\
\hline BignoniaceaeJacaranda micrantha Cham. & Caroba & 1 & 0,84 & - & - & $\mathrm{N}$ \\
\hline $\begin{array}{l}\text { BignoniaceaeTabebuia heptaphylla (Mart.) } \\
\text { Standl }\end{array}$ & Ipê roxo & 7 & 5,88 & 4 & 0,93 & $\mathrm{~N}$ \\
\hline BombacaceaePachira aquatica Aubl. & Munguba & 4 & 3,36 & 19 & 4,44 & $\mathrm{~N}$ \\
\hline CaesalpinaceaeCaesalpinia peltophoroides DC & Sibipiruna & 4 & 3,36 & 7 & 1,64 & $\mathrm{~N}$ \\
\hline $\begin{array}{l}\text { ChrysobalanaceaeLicania tomentosa (Benth.) } \\
\text { Fritsch. }\end{array}$ & Oiti & 47 & 39,50 & 353 & 82,48 & $\mathrm{~N}$ \\
\hline CombretaceaeTerminalia catappa L. & Sete copas & - & - & 1 & 0,23 & $\mathrm{E}$ \\
\hline LauraceaePersea americana & Abacate & 2 & 1,68 & - & - & $\mathrm{E}$ \\
\hline MalpighiaceaeMalpighia glabra L. & Acerola & 1 & 0,84 & - & - & $\mathrm{E}$ \\
\hline MeliaceaeAzadirachta indica A. Juss. & $\mathrm{Nim}$ & - & - & 1 & 0,23 & $\mathrm{E}$ \\
\hline MeliaceaeSwietenia macrophylla King. & Mogno & - & - & 1 & 0,23 & $\mathrm{~N}$ \\
\hline MimosaceaeAcacia albida Del. & Acácia & - & - & 11 & 2,57 & $\mathrm{E}$ \\
\hline $\begin{array}{l}\text { MimosaceaeAnadenanthera macrocarpa (Benth.) } \\
\text { Brenae }\end{array}$ & Angico & 1 & 0,84 & - & - & $\mathrm{N}$ \\
\hline MoraceaeArtocarpus heterophyllus Lam. & Jaqueira & 3 & 2,52 & - & - & $\mathrm{E}$ \\
\hline MoraceaeFicus benjamina & Ficus & 7 & 5,88 & 29 & 6,78 & $\mathrm{E}$ \\
\hline MyrtaceaeSyzygium malaccense & Jambo vermelho & 2 & 1,68 & - & - & $\mathrm{E}$ \\
\hline RutaceaeMurraya paniculata (L.) Jacq. & Murta & 4 & 3,36 & - & - & $\mathrm{E}$ \\
\hline TOTAL & 21 & 119 & 100 & 428 & 100 & \\
\hline
\end{tabular}


A utilização de espécies exóticas à flora brasileira representou 54,5\% das espécies plantadas nas vias na cidade de Colíder e em Matupá, e as espécies exóticas totalizaram $64,7 \%$ do total amostrado. Dados semelhantes foram obtidos em outras localidades do país, onde as espécies exóticas corresponderam à maioria da população, como: Americana/SP - 58,6\% das espécies (SILVA, 2005) e Mariápolis, PR - 63,2\% das espécies exóticas (SILVA et al., 2008). Como se constatou, através desses resultados, o costume de plantar espécies exóticas no meio urbano é prática muito comum nas cidades brasileiras. Entre as espécies nativas do Brasil foi constatada baixa ocorrência de espécies naturais do bioma amazônico, ocorrendo, tradicionalmente, espécies nativas de outras regiões, como é o caso de Licania tomentosa e Caesalpinia peltophoroides (LORENZI, 2008).

O número de espécies aptas à alimentação humana foi significativo em Matupá, onde foram amostradas sete espécies, correspondendo a 22,7\% da população amostrada nessa cidade; e em Colíder, onde foi levantada uma única espécie utilizada, usualmente, para o consumo humano. Foi possível perceber que os plantios de frutíferas, em geral, correspondem a ações não planejadas, de poucos exemplares, feitos de forma espontânea pela população com a finalidade de alimentação humana. Santos e Teixeira (2001) desaconselharam as espécies que produzem frutos grandes, como é o caso de Artocarpus heterophyllus, Mangifera indica e Persea americana, presentes na arborização urbana das cidades estudadas, pois esses frutos podem cair sobre a calçada e sobre veículos ou pedestres. Os frutos podem servir de alimento para vetores de doenças (MILANO e DALCIN, 2000).

O baixo número de espécies arbóreas utilizadas, assim como a distribuição irregular das espécies, pode ser atribuído à ausência de elaboração de legislação específica para atender ao planejamento urbano, nessas cidades. Dessa forma, a escolha das espécies para arborização viária fica sob a responsabilidade dos moradores, refletindo no plantio desordenado de espécies, sem a observância de critérios técnicos.

Os valores do índice de diversidade de Shannon (IDS) foram: 0,76 (Colíder) e 2,24 (Matupá). A análise do IDS reflete a realidade da arborização viária das cidades estudadas, caracterizada por um número muito limitado de espécies. Esses valores são inferiores ao obtidos em estudos de arborização urbana realizados em outras regiões do país. Meneghetti (2003) obteve um IDS de 2,63 para 65 espécies dos bairros da orla marítima de Santos/SP, e na Estância de Águas de São Pedro o valor do IDS foi 3,90 para a arborização viária (SILVA FILHO e BORTOLETO, 2005).

\subsection{Características dendrométricas dos indivíduos arbustivo-arbóreos}

Nas cidades de Matupá e Colíder, 50,4\% e 66,1\% dos indivíduos arbustivo-arbóreos amostrados foram plantados em calçadas sem fiações elétricas e telefônicas, respectivamente. Na cidade de Matupá, apesar do elevado número de indivíduos plantados sob a fiação, 88,1 \% desses indivíduos apresentaram altura total inferior a 6,0 m.

A classe de altura total II $(3<\mathrm{h}<6 \mathrm{~m})$ teve destaque quanto ao número de indivíduos amostrados nas cidades de Matupá (43,7\%) e Colíder (76,9\%) (Figura 1A). Licania tomentosa apresentou maior número de indivíduos amostrados nas classes de altura total I e II, nas duas cidades.

Embora o número de indivíduos com altura superior a 6,0 $\mathrm{m}$ fosse reduzido, há que se considerar que essas espécies poderão atingir maiores alturas, por se tratar de espécies de porte elevado como Mangifera indica e Licania tomentosa (LORENZI, 2006; LORENZI, 2008). Do ponto de vista ambiental, o uso de espécies de médio e grande portes na arborização viária, conforme constatado nas cidades estudadas, é interessante, por serem mais eficientes na geração de benefícios diretos e indiretos (MILANO e DALCIN, 2000).

Quanto à altura da bifurcação das árvores utilizadas na arborização urbana, 84,5\% (Matupá) e 96,7\% (Colíder) dos indivíduos foram agrupados na classe I ( $\mathrm{HB}<1,8 \mathrm{~m}$ ) (Figura 1B).

A alta concentração de indivíduos na primeira classe de altura de bifurcação do tronco, nas duas cidades avaliadas, pode ser indicativo da baixa qualidade das mudas utilizadas na arborização urbana, que pode ser atribuída ao fato de os plantios nessas cidades serem realizados pelos próprios moradores, sem haver preocupação com aspectos técnicos. São Paulo (2005) recomendou que as mudas para plantio devem apresentar, preferencialmente, fuste com altura mínima de 1,8 m e, quando possuírem ramificações laterais abaixo dessa altura após o plantio, ser submetidas à poda de formação. A ocorrência de desgalhamento da árvore desde a base, ou próximo dela, quando esta está plantada nas calçadas pode dificultar a transitação de pedestres. 
Na cidade de Matupá, 65,5\% dos indivíduos amostrados pertenciam à classe diamétrica I (DAS $<0,2 \mathrm{~m}$ ). Já em Colíder 52,3\% dos indivíduos se enquadraram na classe II (0,2 m < DAS < 0,4 m) (Figura 1C). Licania tomentosa foi a espécie mais frequente nas duas cidades, nas classes diamétricas I e II.

O predomínio de indivíduos na classe diamétrica I na cidade de Matupá pode ser atribuído à jovialidade da arborização, uma vez que o processo de urbanização dessa cidade é recente (21 anos). Os resultados obtidos em Colíder indicam que se trata de uma população arbórea já estabelecida, ou seja, com maior participação de indivíduos adultos. Situação semelhante foi detectada em Americana/SP, onde 55\% dos indivíduos apresentaram DAP superior a 0,25 m (SILVA, 2005). Forman e Godran (1986) ressaltaram a necessidade de alto percentual de indivíduos jovens, devido à alta mortalidade nesse período, para se ter um número razoável de indivíduos adultos, quando a população se tornar estável.
Na cidade de Matupá, 42,9\% dos indivíduos foram agrupados na classe de diâmetro de copa II (DC $<3 \mathrm{~m}$ ). Já em Colíder 73,8\% dos indivíduos amostrados pertenceram à classe II (3 m < DC < 6 m) (Figura 1D). Do ponto de vista ambiental, Licania tomentosa, que foi a espécie mais frequente nas duas cidades, apresenta resultados satisfatórios quanto ao sombreamento, pelas características da copa (LORENZI, 2008).

\subsection{Adequação da arborização viária em relação ao espaço disponível}

De acordo com a classificação de São Paulo (2005), todas as ruas amostradas são largas. Uma característica comum entre as duas cidades é a ocorrência de recuos largos, devido ao afastamento dos lotes. Essa disponibilidade de espaço permite o plantio de espécies de médio e grande portes.
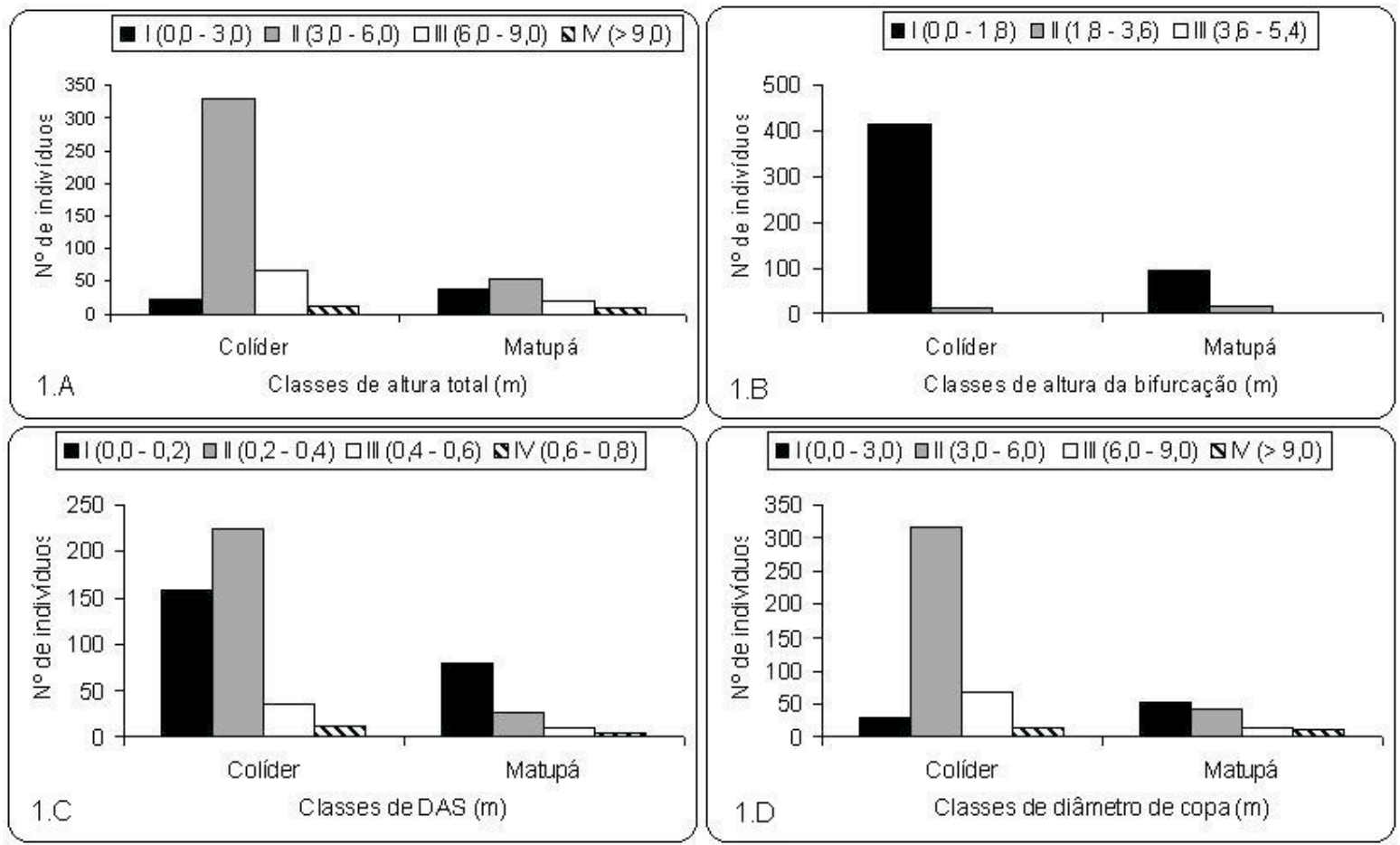

Figura 1 - Características das espécies arbóreas ocorrentes na arborização urbana de duas cidades da região Norte de Mato Grosso; 1A - distribuição da altura total (m) dos indivíduos; 1B - distribuição da altura da bifurcação (m); 1C - distribuição do diâmetro (m) a 0,5 m do solo (DAS); e 1D - distribuição do diâmetro de copa (m) dos indivíduos.

Figure 1 - Characteristics of the tree species occurring in the urban forestry of two cities of the northern region of the State of Mato Grosso; 1-A - distribution of total height $(\mathrm{m})$ individuals; 1-B - distribution of bifurcation height $(\mathrm{m})$; 1-C - distribution of diameter $(\mathrm{m})$ to $0.5 \mathrm{~m}$ of soil (DAS); 1-D-distribution of the diameter of crown $(\mathrm{m})$ of individuals. 
Tabela 3 - Dimensionamento das redes viárias e recuos, altura das árvores e fiações e distanciamento dos componentes urbanos em relação ao meio-fio nas cidades de Colíder e Matupá, situadas na região Norte do Estado de Mato Grosso.

Table 3 - Dimension of road system and setbacks, tree height and wiring and distance of components urban in relation to curb in the cities of Colíder and Matupá, located in the northern region of Mato Grosso State.

\begin{tabular}{|c|c|c|c|c|c|c|c|}
\hline Cidade & $\begin{array}{l}\text { Largura } \\
\text { da via (m) } \\
\text { (méd; mín; } \\
\text { máx) }\end{array}$ & $\begin{array}{l}\text { Largura do } \\
\text { recuo (m) } \\
\text { (méd; mín; } \\
\text { máx) }\end{array}$ & $\begin{array}{l}\text { DPMF } \\
\text { (méd; mín; } \\
\text { máx) }\end{array}$ & $\begin{array}{l}\text { DAMF } \\
\text { (méd; mín; } \\
\text { máx) }\end{array}$ & $\begin{array}{l}\text { Altura da árvore } \\
\text { (m) } \\
\text { (méd; mín; } \\
\text { máx) }\end{array}$ & $\begin{array}{l}\text { AFBT } \\
\text { (méd; mín; } \\
\text { máx) }\end{array}$ & $\begin{array}{l}\text { AFAT } \\
\text { (méd; mín; } \\
\text { máx) }\end{array}$ \\
\hline Colíder & $\begin{array}{c}9,1 ; 7,0 ; 1 \\
10,5\end{array}$ & $\begin{array}{c}5,3 ; 4,0 ; \\
\quad 6,8\end{array}$ & $\begin{array}{l}2,3 ; 0,7 ; \\
4,2\end{array}$ & $\begin{array}{c}4,0 ; 1,7 ; \\
5,5\end{array}$ & $\begin{array}{c}4,7 ; 1,5 ; \\
8,2\end{array}$ & $\begin{array}{c}6,7 ; 6,3 ; \\
7,5\end{array}$ & $\begin{array}{c}9,1 ; 9,0 ; \\
10\end{array}$ \\
\hline Matupá & $\begin{array}{c}7,4 ; 7,0 ; 8,2 \\
8,2\end{array}$ & $\begin{array}{c}3,0 ; 2,8 ; 3,6 \\
3,6\end{array}$ & 1,$4 ; \frac{1,0 ;}{1,5}$ & $\begin{aligned} 2,5 ; & 2,1 ; 3,2 \\
3,2 & \end{aligned}$ & $\begin{array}{c}3,0 ; 0,8 ; 8,5 \\
8,5\end{array}$ & $\begin{array}{c}6,4 ; 6,0 ; 7,0 \\
7,0\end{array}$ & $\begin{array}{c}8,6 ; 8,0 ; \\
9,0\end{array}$ \\
\hline
\end{tabular}

DPMF = distância do poste ao meio-fio (m); DAMF = distância da árvore ao meio-fio (m); AFBT = altura da fiação de baixa tensão $(\mathrm{m})$; AFAT = altura da fiação de alta tensão $(\mathrm{m})$; méd = média; mín = mínimo; e máx = máximo.

$D P M F=$ distance from the pole to the curb $(m) ; D A M F=$ distance from the tree to the curb $(m)=$ AFBT time of low voltage wiring $(m)=$ height Afat high voltage wiring $(m) ;$ avg = average; $\min =$ minimum, and max $=$ maximum.

De acordo com a Tabela 3, em todas as cidades a distância média entre o local de plantio das espécies e o alinhamento da fiação é superior a $1 \mathrm{~m}$. Entretanto, com base nas distâncias mínimas, possivelmente em alguns pontos as árvores estejam exatamente sob a fiação. Conforme os dados médios, nas cidades estudadas ainda não há intensa concorrência direta das copas com a fiação de baixa e alta tensões, haja vista que a altura média dos indivíduos nas proximidades da rede elétrica nas duas cidades era inferior a 6,0 m.

Segundo São Paulo (2005), o plantio de árvores de grande porte sob a rede elétrica é possível, desde que a muda não seja plantada no alinhamento da rede e que a copa das árvores seja conduzida precocemente, através do trato cultural adequado, acima dessa rede. É importante considerar, nessa situação, a adequação do sistema de distribuição de energia, de forma a reduzir os conflitos e, consideravelmente, os gastos preventivos e corretivos para manutenção da rede elétrica e da arborização conjuntas (BRITO e CASTRO, 2007).

Conforme a Tabela 3, nas duas cidades avaliadas as árvores são plantadas próximas aos muros, estando acima da recomendação técnica de Milano (1988), que é $1 \mathrm{~m}$ de distância do meio-fio. Em decorrência de recuos largos, o grau de sombreamento das vias é baixo.

A estimativa da distância média entre árvores obteve os seguintes valores médios: Colíder (14,0 m) e Matupá (15,1 m). Os resultados apontaram número razoável de árvores plantadas nas ruas das cidades estudadas, no entanto se encontravam acima da recomendação técnica. De acordo com São Paulo (2005), as árvores de portes médio e grande devem ser plantadas em espaçamentos mínimos de 8,0 e 12,0 m, respectivamente.
A densidade de árvores/ $\mathrm{km}$ de calçada estimado nas cidades avaliadas obteve os seguintes valores: 66,2 (Matupá) e 71,3 (Colíder), estando, dessa forma, acima da densidade estimada por Rossatto et al. (2008) na cidade de Assis, SP (37,9 árvores/km de calçada). Entretanto, os valores ficaram abaixo do obtido por Silva Filho e Bortoleto (2005), na cidade de Águas de São Pedro (130 árvores/km).

Foram encontradas árvores plantadas próximas aos elementos urbanos nas duas cidades estudadas, no que se refere à distância da árvore ao poste, esquina e placas de sinalização de trânsito. Porém, o número de árvores, nessa situação, apresentou baixa representatividade em relação ao número total de indivíduos amostrados.

\section{CONCLUSÃO}

A arborização viária, nas duas cidades estudadas, apresenta número reduzido de espécies, aliado à frequência irregular destas, nas vias amostradas, e a cidade de Colíder apresentou as espécies distribuídas de maneira mais crítica, em comparação com as outras duas cidades. Foi amostrado número significativo de espécies frutíferas na cidade de Matupá, e o plantio dessas espécies não é recomendado nas vias públicas.

Além da distribuição irregular das espécies, algumas falhas detectadas na arborização das cidades estudadas, como a altura da bifurcação inferior a $1,80 \mathrm{~m}$ na maior parte dos indivíduos, em plantio realizado próximo aos muros e indivíduos de estatura muito pequena, podem comprometer a qualidade da arborização viária. 
Licania tomentosa foi a espécie mais frequente nas duas cidades, mostrando-se adaptada aos ambientes urbanos da região. No entanto, a frequência de plantio excessivamente alta não é recomendada. Todas as cidades avaliadas devem procurar a introdução de novas espécies arbustivas e arbóreas nativas da região na arborização viária, haja vista que o uso de espécies exóticas foi predominante.

Podem ocorrer conflitos entre as árvores das redes viárias com a fiação elétrica e da telefônica, devido ao uso de espécies de porte elevado sob a fiação, sem planejamento.

Por conta de deficiências no planejamento da arborização urbana das cidades estudadas, as árvores foram plantadas distantes do meio-fio, sendo, consequentemente, o grau de sombreamento das vias e calçadas reduzido.

\section{REFERÊNCIAS}

BIONDI, D.; MACEDO, J. H. P. Plantas invasoras encontradas na área urbana de Curitiba (PR).

Floresta, v.38, n.1, p.129-144, 2008.

BORTOLETO, S. et al. Composição e distribuição da arborização viária da estância de Águas de São Pedro-SP. Revista da Sociedade

Brasileira de Arborização Urbana, v.2, n.3, p.32-46, 2007.

BRITO, M. L. S.; CASTRO, P. M. Viabilidade econômica de redes de distribuição protegidas.

Revista da Sociedade Brasileira de Arborização Urbana, v.2, n.1, p.130-137, 2007.

CARVALHO, P. E. R. Espécies arbóreas brasileiras. Brasília: Embrapa Informação Tecnológica, 2003. v.1. 1039p.

CARVALHO, P. E. R. Espécies arbóreas brasileiras. Brasília: Embrapa Informação Tecnológica, 2006. v.2. 627p.

CARVALHO, P. E. R. Espécies arbóreas brasileiras. Brasília: Embrapa Informação Tecnológica, 2008. v.3. 593p.

CORREA, M. P. Dicionário das plantas úteis do Brasil e das exóticas cultivadas. Rio de Janeiro: IBDF, 1984. 6v.
FORMAN, R. T. T.; GODRAN, M. Landscape ecology. New York: John Wiley, 1986. 620p.

GONÇALVES, E. O. et al. Avaliação qualitativa de mudas destinadas à arborização urbana no estado de Minas Gerais. Revista Árvore, v.28, n.4, p.479-486, 2004.

LORENZI, H. Árvores brasileiras: manual de identificação e cultivo de plantas arbóreas nativas do Brasil. 2.ed. Nova Odessa: Instituto Plantarum, 2002. v.2. 382p.

LORENZI, H. et al. Árvores exóticas no Brasil: madeireiras, ornamentais e aromáticas. Nova Odessa: Instituto Plantarum, 2003. 384p.

LORENZI, H. et al. Frutas brasileiras e exóticas cultivadas: de consumo in natura. Nova Odessa: Instituto Plantarum, 2006. 640p.

LORENZI, H. Árvores brasileiras: manual de identificação e cultivo de plantas arbóreas nativas do Brasil. 5.ed. Nova Odessa: Instituto Plantarum, 2008. v.1. 368p.

MASCARÓ, L. E. A. R.; MASCARÓ, J. L.

Vegetação urbana. 2.ed. Porto Alegre: Mais Quatro, 2005. 204p.

MATO GROSSO. Informativo

socioeconômico de Mato Grosso: 2005.

Cuiabá: Central de Texto, 2005.

MATO GROSSO. Secretaria de Estado de Planejamento. Anuário estatístico de Mato Grosso de 2007. Cuiabá: Carlini e Caniato Editorial, 2008. 762p.

McHALE, M. R.; McPHERSON, E. G.; BURKE, I. C. The potential of urban tree plantings to be cost effective in carbon credit markets. Urban Forestry and Urban Greening, v.6, p.46-60, 2007.

MELO, R. R.; LIRA FILHO, J. A.; RODOLFO JÚNIOR, F. Diagnóstico qualitativo e quantitativo da arborização urbana no bairro Bivar Olinto, Patos, Paraíba. Revista da Sociedade Brasileira de Arborização Urbana, v.2, n.1, p.64-78, 2007.

Revista Árvore, Viçosa-MG, v.34, n.5, p.899-906, 2010 
MENEGHETTI, G. I. P. Estudo de dois métodos de amostragem para inventário da arborização de ruas dos bairros da orla marítima do município de Santos-SP. 2003. 100f. Dissertação (Mestrado em Recursos Florestais) Escola Superior de Agricultura Luiz de Queiroz, Piracicaba, 2003.

MILANO, M. S.; DALCIN, E. C. Arborização de vias públicas. Rio de Janeiro: Light, 2000. 226 p.

MILANO, M. S. Avaliação e análise da arborização de ruas de Curitiba-PR. 1984. 130f. Dissertação (Mestrado em Ciências Florestais) - Universidade Federal do Paraná, Curitiba, 1984.

ROCHA, R. T.; LELES, P. S. S.; OLIVEIRA NETO, S. N. Arborização de vias públicas em Nova Iguaçu, RJ: o caso dos Bairros Rancho Novo e Centro. Revista Árvore, v.28, n.4, p.599-607, 2004.

ROSSATTO, D. R.; TSUBOY, M. S. F.; FREI, F. Arborização urbana na cidade de Assis-SP: uma abordagem quantitativa. Revista da

Sociedade Brasileira de Arborização Urbana, v.3, n.3, p.1-16, 2008.

SANTOS, N. R. Z.; TEIXEIRA, I. F.

Arborização de vias públicas: ambiente $x$ vegetação. Santa Cruz do Sul: Instituto Souza Cruz, 2001. 135p.
SÃO PAULO. Secretaria Municipal do Verde e do Meio Ambiente. Manual técnico de arborização urbana. 2.ed. São Paulo: Nacional, 2005. 45p.

SHANLEY, P.; MEDINA, G. (Eds.) Frutíferas e plantas úteis na vida amazônica. Belém: CIFOR, 2005. 296p.

SILVA FILHO, D. F.; BORTOLETO, S. Uso de indicadores de diversidade na definição de plano de manejo da arborização viária de águas de São Pedro - SP. Revista Árvore, v.29, n.6, p.973-982, 2005.

SILVA, L. F. Situação da arborização viária e proposta de espécies para os bairros Antônio Zanaga I e II, da cidade de Americana/SP. 2005. 80f. Dissertação (Mestrado em Agronomia) - Escola Superior de Agricultura Luiz de Queiroz, Piracicaba, 2005.

SILVA, L. M. et al. Inventário da arborização em duas vias de Mariópolis/PR. Revista da Sociedade Brasileira de Arborização Urbana, v.3, n.1, p.36-53, 2008.

VELASCO, G. D. N.; LIMA, A. M. L.; COUTO, H. T. Z. Análise comparativa dos custos de diferentes redes de distribuição de energia elétrica no contexto da arborização urbana. Revista Árvore, v.30, n.4, p.679-686, 2006.

YANG, J. et al. The urban forest in Beijing and its role in air pollution reduction. Urban Forestry and Urban Greening, v.3, p.65-78, 2005. 